\title{
SPEECH THERAPY TELEPRACTICE FOR VOCAL CORD DYSFUNCTION (VCD): MAINECARE (MEDICAID) COST SAVINGS
}

\author{
MICHAEL P. TOWEY, MA, CCC-SLP, F-ASHA \\ Waldo County General Hospital, Voice \& SWAllowing Center of Maine, Belfast, Maine
}

\section{ABSTRACT}

This Brief Communication represents an analysis of the cost savings to MaineCare (also referred to as Medicaid) directly attributable to service provided via speech therapy telepractice. Seven female (primarily adolescent) MaineCare patients consecutively referred to Waldo County General Hospital (WCGH) with suspected diagnosis of Vocal Cord Dysfunction (VCD) were treated by speech therapy telepractice. Outcome data demonstrated a first month cost savings of $\$ 2376.72$. The analysis additionally projected thousands of dollars of potential savings each month in reduced medical costs for this patient group as a result of successful treatment via speech therapy telepractice. The study suggests that without access to speech therapy telepractice for patients with VCD, the medical costs to MaineCare will be ongoing and significant.

Keywords: Speech therapy, telepractice, vocal cord dysfunction (VCD), cost savings

\section{BACKGROUND/RATIONALE}

The efficacy of telemedicine and telerehabilitation in treating medical disorders has been established for more than 20 years. The direct cost benefits are now being recognized on a federal level, with CMS Medicaid stating: "Telemedicine is viewed as a cost-effective alternative to the more traditional face-to-face way of providing medical care" (Centers for Medicare \& Medicaid Services, 2012).

This Brief Communication represents an analysis of the cost savings to MaineCare (also referred to as Medicaid) directly attributable to service provided via speech therapy telepractice for Vocal Cord Dysfunction (VCD) by telepractitioners at Waldo County General Hospital (WCGH). WCGH recognizes the responsibility to provide high quality outcomes to all Maine citizens, via services that reduce the cost of health care delivery. The speech therapy department at WCGH has therefore created a model of service delivery that requires less treatment at less cost, while achieving outcomes that are equal to or exceed national benchmarks (WCGH, 2012).

VCD, also termed Paradoxical Vocal Fold Motion (PVFM), was initially identified and described in 1983 by a multi-disciplinary team led by Kent Christopher, MD at National Jewish Hospital in Denver, CO. (Blager, 2006; 2008). VCD is an abnormal spasm of the vocal folds and laryngeal system that blocks the airway and renders inhalation difficult or impossible. VCD can be triggered by exercise, odors, swallowing, stress, or a hypersensitive reaction of the throat to an irritation. This condition can create heightened anxiety and fear in patients, with many reporting that during a VCD episode, they thought they might die. VCD most often affects women, with a subgroup of young female athletes who are affected.

It is not unusual for VCD to be undiagnosed for months and even years, resulting in high costs of unnecessary medication, diagnostic testing, and repeat physician office visits. VCD is often mistaken for asthma and treated with a standard course of medications and inhalers. Emergency room visits often ensue when these patients are unable to breathe -- potentially triggering invasive procedures such as intubation or tracheostomy.

Some VCD referrals are complex cases with no qualified provider in their communities; some have previously had failed treatment; and some have multiple associated medical diagnoses. At WCGH/Speech Language Pathology, one woman was seen with a 43 year history of the disorder. Another patient was a young female athlete with a five year history of VCD following a near drowning event. Another female athlete who presented with more than 100 emergency room and hospital admissions before being properly diagnosed and successfully treated.

The standard of practice for VCD is treatment by a speech-language pathologist (National Jewish Health, 2012). When correctly diagnosed and properly treated, total symptom relief can be expected in 6-8 speech 
therapy visits, and is often achieved in 1-4 visits by incorporating voice facilitation and vocal performance techniques (Ricker \& Towey, 2007).

WCGH has developed specialized expertise in the treatment of this disorder and receives referrals from medical specialists throughout Maine for evaluation and treatment of VCD patients. At WCGH, VCD patients are routinely treated in 2-4 visits. An initial onsite evaluation is completed that includes endoscopic visualization of laryngeal positioning. The examination incorporates environmental challenges to induce symptoms. Follow-up treatment is most typically by speech therapy telepractice due to barriers of long travel distances for return visits, access to qualified providers, and the effectiveness of speech therapy telepractice.

The correct treatment for VCD results in reduced use of or elimination of medications; reduced physician office and emergency room visits; and reduced costs in diagnostic medical procedures. When properly managed, patients with VCD are able to resume normal activities of daily living.

\section{RESEARCH}

\section{STUDY DESIGN:}

Consecutive MaineCare patients referred to speech therapy at WCGH were selected for retrospective review, all diagnosed with the same disorder (VCD). Prior to referral/treatment, all patients had sustained ongoing costs to MaineCare for treatment of symptoms.

The independent variable in the successful treatment outcomes for all these MaineCare patients was access to skilled speech therapy and telepractice. The patients were offered the option of a return in-person visit to the WCGH speech therapy department. All refused in-office treatment due to distance, cost of travel, time involved in travel, caregiver burden or difficulty arranging transportation. Instead, the seven patients selected treatment by speech therapy telepractice.

\section{STUDY GROUP:}

The group (summarized in Table 2) of consecutive MaineCare patients diagnosed with VCD lived an average of 67 miles from WCGH (range: 14-143 miles). All were females with a mean age of 17.4 years (range 11-38 years). Onset of symptoms ranged from five years to several months. All had been treated with standard procedures of medications, repeat office visits, and emergency room visits. Some had failed to improve with previous traditional therapy approaches.

\section{RESULTS:}

Seven consecutive MaineCare patients with a diagnosis of Vocal Cord Dysfunction (VCD) were treated by speech therapy telepractice at a cost of $\$ 667.94$ to MaineCare (MaineCare provider rate). (Table 1) Treatment resulted in successful outcomes for the entire group. Further medical tests were canceled, related medications were discontinued, and repeat physician and emergency room visits for treatment of symptoms were eliminated.

\section{Table 1}

Monthly MaineCare Costs \& Savings Speech Therapy Telemedicine

\begin{tabular}{l|l|l|}
\hline Cost & Cost & Savings \\
\hline Before telepractice & Speech telepractice & One Month \\
\hline 3035.66 & $\$ 667.94$ & $\$ 2367.72$ \\
\hline
\end{tabular}

In contrast, in the month prior to referral to the WCGH speech therapy department for evaluation and treatment, MaineCare was responsible for $\$ 3035.16$ in medical expenses for this group. Based upon the costs related to this condition accrued in the month preceding telepractice, the first month cost savings to MaineCare was $\$ 2376.72$ (Table 1), a $72 \%$ cost reduction. These savings would not have been possible without access to speech therapy telepractice. 


\begin{tabular}{|c|c|c|c|c|}
\hline \multicolumn{5}{|c|}{ Table 2} \\
\hline \multicolumn{2}{|c|}{$\begin{array}{l}\text { Patient } \\
\text { age/gender } \\
\text { Distance from } \\
\text { WCGH }\end{array}$} & \multirow{2}{*}{$\begin{array}{l}\text { History } \\
\\
\text { Onset six months prior. } \\
\text { Pulmonary Function Test (PFT). } \\
\text { No asthma. }\end{array}$} & \multirow{2}{*}{$\begin{array}{l}\text { Speech Therapy Telepractice } \\
\text { Intervention s } \\
\text { Two speech therapy telepractice } \\
\text { visits. }\end{array}$} & \multirow{2}{*}{$\begin{array}{l}\text { Outcomes } \\
\\
\text { Symptoms resolved. } \\
\text { Albuterol \& Flovent } \\
\text { discontinued. }\end{array}$} \\
\hline 1 & $\begin{array}{l}14 \mathrm{y} / \mathrm{o} \\
\text { female } \\
74 \text { miles }\end{array}$ & & & \\
\hline 2 & $\begin{array}{l}13 \mathrm{y} / \mathrm{o} \\
\text { female } \\
44 \text { miles }\end{array}$ & $\begin{array}{l}\text { Intermittent, several years. } \\
\text { Pediatrician referral; considering } \\
\text { PFT. }\end{array}$ & $\begin{array}{l}\text { Two speech therapy telepractice } \\
\text { visits. }\end{array}$ & $\begin{array}{l}\text { Symptoms resolved. } \\
\text { Order for PFT methacholine } \\
\text { challenge cancelled by } \\
\text { pediatrician. }\end{array}$ \\
\hline 3 & $\begin{array}{l}38 \text { y/o } \\
\text { female } \\
24 \text { miles }\end{array}$ & $\begin{array}{l}\text { History of gastroesophageal } \\
\text { reflux disease (GERD) w/Nissan } \\
\text { Fundoplication, VCD, asthma. } \\
\text { Anxiety, twice monthly ER visits. }\end{array}$ & $\begin{array}{l}\text { Four treatments, two/office, } \\
\text { two/speech therapy telepractice } \\
\text { visits. }\end{array}$ & $\begin{array}{l}\text { Symptoms resolved. } \\
\text { Eliminated twice monthly ER } \\
\text { visits. }\end{array}$ \\
\hline 4 & $\begin{array}{l}16 \text { y/o } \\
\text { female } \\
33 \text { miles }\end{array}$ & $\begin{array}{l}\text { Multiple episodes of VCD; } \\
\text { GERD. Repeated ER visits. } \\
\text { Albuterol. } \\
\text { Previous therapy did not help }\end{array}$ & $\begin{array}{l}\text { Two speech therapy telepractice } \\
\text { visits. }\end{array}$ & $\begin{array}{l}\text { Symptoms resolved. } \\
\text { PFT normal. } \\
\text { ProAir HFA } 108 \\
\text { discontinued. } \\
\text { Eliminated one time monthly } \\
\text { ER visits. }\end{array}$ \\
\hline 5 & $\begin{array}{l}11 \mathrm{y} / \mathrm{o} \\
\text { female } \\
73 \text { miles }\end{array}$ & $\begin{array}{l}\text { VCD, cough symptoms } 4-5 \\
\text { years. }\end{array}$ & $\begin{array}{l}\text { One speech therapy telepractice } \\
\text { visit. }\end{array}$ & $\begin{array}{l}\text { No repeat symptoms. } \\
\text { Eliminated repeat PCP visits } \\
\text { for symptoms. }\end{array}$ \\
\hline 6 & $\begin{array}{l}15 \mathrm{y} / \mathrm{o} \\
\text { female } \\
89 \text { miles }\end{array}$ & $\begin{array}{l}\text { VCD, periods of aphonic onset } \\
\text { (one year), repeated primary } \\
\text { care physician (PCP) visits for } \\
\text { symptoms. }\end{array}$ & $\begin{array}{l}\text { One speech therapy telepractice } \\
\text { visit. }\end{array}$ & $\begin{array}{l}\text { Symptoms fully resolved. } \\
\text { Eliminated repeat PCP visits } \\
\text { for symptoms. }\end{array}$ \\
\hline 7 & $\begin{array}{l}15 \text { y/o } \\
\text { female } \\
143 \\
\text { miles }\end{array}$ & $\begin{array}{l}\text { ADHD/ODD } \\
\text { Pre treats with inhaler before } \\
\text { exercise and during episodes. } \\
\text { Intense throat clearing/coughing } \\
\text { resulting in recurrent PCP visits. }\end{array}$ & $\begin{array}{l}\text { One speech therapy telepractice } \\
\text { visit. }\end{array}$ & $\begin{array}{l}\text { Symptoms resolved. } \\
\text { Discontinued Pro Air inhaler } \\
\text { use. } \\
\text { Challenged with variety of } \\
\text { noxious elements, with no } \\
\text { response. } \\
\text { Eliminated repeat PCP visits } \\
\text { for symptoms. }\end{array}$ \\
\hline \multicolumn{5}{|c|}{ Cost Basis } \\
\hline \multicolumn{5}{|c|}{$\begin{array}{l}\text { Walgreens pharmacy (Maine, 2011): Flovent } \$ 197.99 \text {; Albuterol } \$ 10.99 \text {; ProAir HFA 108: } \$ 59.99 \\
\text { WCGH: Pulmonary Function Test (PFT): } \$ 299.00 \text {; Methacholine challenge: } \$ 607.10 \text {; Emergency Room visit: } \$ 500.00 \\
\text { (minimum); MD office visit: } \$ 60 \text { (minimum). }\end{array}$} \\
\hline
\end{tabular}

As shown in Table 2, the eliminated expenses included physician office visits, emergency room visits, planned medical evaluations, and prescription medications. Telepractice therefore eliminated the need for repeat expensive medical encounters, (e.g., emergency room visits; Methacholine or bronchial challenges; pulmonary function testing (PFT)) and medication use (e.g., Albuterol; Flovent; ProAir HFA 108).
These outcomes have produced ongoing savings to MaineCare in the range of $\$ 2300$ to $\$ 3000$ per month. Patients remained symptom free at the one-year follow-up by phone interview.

Without the telepractice interventions, MaineCare would continue to accrue thousands of dollars in ongoing monthly medical costs until these patients are effectively treated, "age out" of MaineCare coverage or become ineligible. 


\section{CONCLUSIONS}

Lack of qualified provider in their home communities, failed previous treatment and low economic status/limited transportation had resulted in increased costs of medical care to MaineCare for seven patients with suspected Vocal Fold Dysfunction (VCD). VCD is a condition characterized by an abnormal spasm of the vocal folds and laryngeal system that blocks the airway and renders inhalation difficult or impossible.

Without access to the treatment provided by speech therapy telepractice, these patients would have continued to experience chronic symptoms resulting in costly and unnecessary medical care. The nature of the disorder is that VCD symptoms (and the associated medical costs) would have continued for months or years. This is the consistent pattern observed at WCGH in more than 100 clinical cases over the last five years.

Due to geographic isolation, lack of providers, and limited access to transportation, it is not likely these patients could have returned to WCGH for speech therapy treatment. If some return visits to WCGH could have been completed, there would have been additional costs to MaineCare in paying for required transportation to a medical appointment.

Vocal Fold Dysfunction (VCD) is just one of a host of preventable and/or treatable conditions for which the use of telepractice might result in significant cost-savings for patients (e.g., reduced costs for transportation, caregivers, and/or lost income), insurers, and society. It is incumbent upon telepractioners to identify other such conditions, and demonstrate the potential savings.

\section{REFERENCES}

1. Blager, F.B. (2000). Paradoxical Vocal Fold Movement: Diagnosis and management. Current Opinions in Otolaryngology and Head \& Neck Surgery, 8, 180-183.

2. Blager, F.B. (2008). Symptoms and treatment of Vocal Cord Dysfunction/Paradoxical Vocal Fold Motion. Paper presented at the American Speech-Language Hearing Association Annual Convention, Chicago, IL, USA. http:// www.asha.org/Events/convention/handouts/2008/1371_ Blager_Florence/

3. Centers for Medicare \& Medicaid Services. (2012). Telemedicine. Retrieved from http://www.medicaid. gov/Medicaid-CHIP-Program-Information/By-Topics/ Delivery-Systems/Telemedicine.html

4. National Jewish Health. (2012). Vocal Cord Dysfunction (VCD): Treatment. Retrieved from http://www. nationaljewish.org/healthinfo/conditions/vcd/treatment/

5. Ricker, E., \& Towey, M. (2007). Outside the box: Voice facilitation and vocal performance techniques. A unique treatment approach for VCD. Paper presented at the 3ro Annual National Conference on Vocal Cord Dysfunction, National Jewish Medical and Research Center, Denver, CO, USA.

6. Waldo County General Hospital. (2012). Proven results using national benchmarks: National Outcomes Measurement System (NOMS). Retrieved from http:// www.mainespeechtherapy.org/content/4062/Proven_ Results/ 